\title{
Propuesta de herramienta para la medición de habitabilidad en viviendas en el Ecuador
}

\author{
Tool proposal for measuring habitability in Ecuador's homes \\ DOI: $\underline{\text { https://doi.org/10.33262/rmc.v6i1.1158 }}$
}

\begin{abstract}
Yandri Muñoz Chavarría ${ }^{1}$
Estudiante del Programa de Maestría Académica con Trayectoria Profesional en Ingeniería Civil, mención Construcción de Vivienda Social del Instituto de Posgrado de la Universidad Técnica de Manabí, Ecuador

(iD https://orcid.org/0000-0002-2076-2200 yanicivil@hotmail.com

Jacqueline Domínguez Gutiérrez ${ }^{2}$

Universidad Laica "Eloy Alfaro “de Manabí, Ecuador

(iD https://orcid.org/0000-0001-8426-3999 jacqueline.dominguez@uleam.edu.ec

Olga Varinia Briones Ordoñez ${ }^{3}$

Universidad Técnica de Manabí, Ecuador

https://orcid.org/0000-0002-7986-4842

olga.briones@utm.edu.ec
\end{abstract}

\section{RESUMEN}

Introducción. Actualmente en Ecuador, los proyectos relacionados con el sector vivienda con cierto interés social, no logran integrar criterios de habitabilidades básicos; lo cual condiciona de manera adversa los niveles de confort y seguridad. Esto se deriva por la ausencia de una herramienta contextualizada para medir la habitabilidad que, a su vez, afecta directamente el bienestar de las personas que las habitan. En el territorio ecuatoriano, no existe una matriz u otro instrumento que sirva para medir la habitabilidad, por lo tanto, es necesario evaluar la posibilidad de crear una, ajustada a la realidad local por su condición generadora de información acerca de los índices en materia físico espacial, psicosocial y socioeconómico. Objetivo. Desarrollar una herramienta que permita medir la habitabilidad en las viviendas de interés social en el Ecuador. Metodología. El estudio fue de enfoque mixto, por las cuales se realizaron las siguientes actividades: analizar las herramientas para medir habitabilidad en el contexto internacional, estudiar el marco regulatorio existente en el contexto nacional, definir los estándares sobre los cuales se debe medir la habitabilidad de acuerdo a las condiciones específicas en el Ecuador, generar una matriz para medir la habitabilidad y demostrar su aplicabilidad en un caso de estudio. La investigación fue aplicada en el Conjunto Habitacional 6 de diciembre (Etapa II), ubicado en la ciudad de Chone, provincia de Manabí. Resultados. Se obtuvo como resultado que las viviendas presentan una valoración de habitabilidad del $37.70 \%$ considerado deficiente. Conclusión. Esta herramienta podrá ayudar en un futuro a todos los entes que participan en la concepción de estos programas de vivienda de interés social.

PALABRAS CLAVE: Habitabilidad; Indicadores; Matriz de medición de habitabilidad; Vivienda social. 


\begin{abstract}
Introduction. Currently in Ecuador, projects related to the housing sector with a certain social interest, fail to integrate basic habitability criteria; which adversely conditions comfort and safety levels. This is derived from the absence of a contextualized tool to measure habitability which, in turn, directly affects the well-being of the people who inhabit them. In the Ecuadorian territory, there is no matrix or other instrument that serves to measure habitability; therefore, it is necessary to evaluate the possibility of creating one, adjusted to the local reality due to its condition that generates information about the indices in physical matter. spatial, psychosocial and socioeconomic. Objective. Develop a tool to measure habitability in low-income housing in Ecuador. Methodology. The study was of a mixed approach, for which the following activities were carried out: analyze the tools to measure habitability in the international context, study the existing regulatory framework in the national context, define the standards on which habitability should be measured according to to the specific conditions in Ecuador, generate a matrix to measure habitability and demonstrate its applicability in a case study. The research was applied in the Housing Complex December 6 (Stage II), located in the city of Chone, province of Manabí. Results. It was obtained as a result that the dwellings present a habitability assessment of $37.70 \%$ considered deficient. Conclusion. This tool will be able to help all the entities that participate in the conception of these social housing programs in the future.
\end{abstract}

KEYWORDS: Habitability; habitability measurement matrix; indicators; social housing

\title{
INTRODUCCIÓN
}

Para Aristóteles el ser humano es catalogado por naturaleza un ente social (Bueno, 2018). Esto conlleva a ubicarlo en una dimensión que busca desarrollar su personalidad, la cual puede estar integrada por elementos intrínsecos de convivencias, necesarias para el desenvolvimiento como individuo. Considera la autora, que las dimensiones individuales del ser, se encuentran adheridas a cualidades naturales que se asocian al reconocimiento y exploración sobre la conducta y el comportamiento del hombre, necesarias para lograr niveles de convivencia en las comunidades y, beneficiarse de manera conjunta. A este proceso se le conoce como sociabilización.

En relación a lo anterior, manifiesta Moreno (2008) que ese proceso conjuga una serie de estudios (económicos, políticos, psico-social, cultural, etcétera), donde la calidad de vida pasa a ser un factor determinante entre las preferencias del ser humano, debido a que los seres humanos son personas que tienen diferentes aspiraciones y ambiciones por naturaleza empírica y racional. El hombre se encuentra envuelto en constantes cambios producto de la evolución socio histórica y avances tecnológicos, que permite la integración de elementos de crecimientos según el grado de desarrollo que experimenta la persona en el entorno que se desenvuelve. 
Agrega la autora, que con el pasar del tiempo se vienen instaurando desde diferentes enfoques complejos vivenciales, aspectos que se inclinan hacia la apertura de brechas culturales, comunicacionales y conductuales; con miras a establecer una medición concreta de todos los componentes que intervienen en una sociedad como, por ejemplo, la habitabilidad. Partiendo de esta perspectiva, esta investigación tiene como objetivo desarrollar una herramienta que permita la medición efectiva y eficiente, sobre el estatus de la habitabilidad en viviendas de interés social en el Ecuador, específicamente en la ciudad de Chone, provincia de Manabí.

\section{DESARROLLO}

El proceso de sociabilización es conocido como el conjunto de aprendizajes que el hombre necesita para relacionarse con autonomía, autorrealización y autorregulación dentro de una sociedad (Link y Greene, 2020). Para lograr concatenar los objetivos que persigue este proceso, es importante la incorporación de elementos sociales principales como la habitabilidad, con el fin de que el ser humano mejore la capacidad para relacionarse en una comunidad. Un nivel aceptable de habitabilidad, es la que se enfila a resolver la precariedad habitacional de los diferentes sectores urbanos.

Autores como Stockebrand y Stockebrand (2021) y Spink et al. (2020), señalan que la habitabilidad son aquellas condiciones en las que una familia ocupa una vivienda. Se encuentran determinadas por las características físicas habitacional, la percepción que tienen las personas sobre tales características, así como por factores psicosociales y socioeconómicos que emergen desde el seno familiar. Asimismo, Corral-Verdugo et al. (2011) y Landázuri y Mercado (2004) sostienen que la vivienda dentro del escenario de la interacción familiar, probablemente conlleva a que la satisfacción promovida por la habitabilidad, pueda manifestarse en patrones de convivencia positiva entre los integrantes de un grupo familiar.

En un contexto social globalizado, la habitabilidad surgió en Europa durante la Revolución Industrial por lo que, en lugares como España, se tiene un interés mayor en la satisfacción del espacio con diversas soluciones (Tarchópulos y Ceballos, 2003 y Molar y Aguirre, 2013). Al hablar de habitabilidad, se analizan las situaciones que se presentan en los países de América Latina y del Caribe, en función a los datos emitidos por el Banco Interamericano de Desarrollo (2012), 59 millones de personas no cuentan con una vivienda apropiada.

Considerando el contexto ecuatoriano, en función a lo emitido en el censo poblacional del 2010 por el Instituto Nacional de Estadísticas y Censos (INEC, 2010), el déficit fue del $18,88 \%$ en el rubro de habitabilidad bajo una estimación cuantitativa, por otra parte, el déficit cualitativo se identificó en el 33,12\%. Por ello, se estima que el $52 \%$ de la población evaluada ha presentado algún tipo de inconveniente en el lugar en donde reside. Autores como Castro et al. (2001), Navarro y Calderón (2014) y Caballero et al. (2017), opinan que la habitabilidad es una cualidad dirigida a satisfacer consecuente las necesidades y aspiraciones del habitante. 
A todas estas, Páramo et al. (2018) argumentan que un espacio se considera habitable en tanto satisface necesidades humanas de quienes lo ocupan. Sin embargo, Cruz-Muñoz e Isunza (2017) consideran que un espacio habitable es el que permite que la vida cotidiana se organice dentro de un espacio de vida polifuncional. De la misma forma, Hastings (2008), Salinas y Pardo (2020) y Caballero et al. (2017), definen la habitabilidad como el grado de adecuación entre el habitante y el espacio construido, y el nivel en que las necesidades habitacionales son satisfechas para cada familia. Ratificando Rodríguez y Villazón (2021) y Usobiaga et al. (2017), que el principal objetivo se concentra en alcanzar los requisitos mínimos de habitabilidad (necesidad, satisfacción y bienestar), que garanticen que una vivienda sea confortable o cómoda para el individuo que vive en ella.

Entre esas requisiciones necesarias, existen unas que son determinadas como básicas por Maslow (1975), el cual las clasifica bajo cinco categorías (ver Figura 1). Lo que se busca es que el sujeto, pueda cubrir necesidades ubicadas en niveles bajos, es decir, más objetivas; con miras a generar aptitudes motivadoras, que coadyuven a impulsar el abastecimiento de poder satisfacer esas carentes y esquivas necesidades, para elevarlas sistemáticamente a un orden más subjetivo.

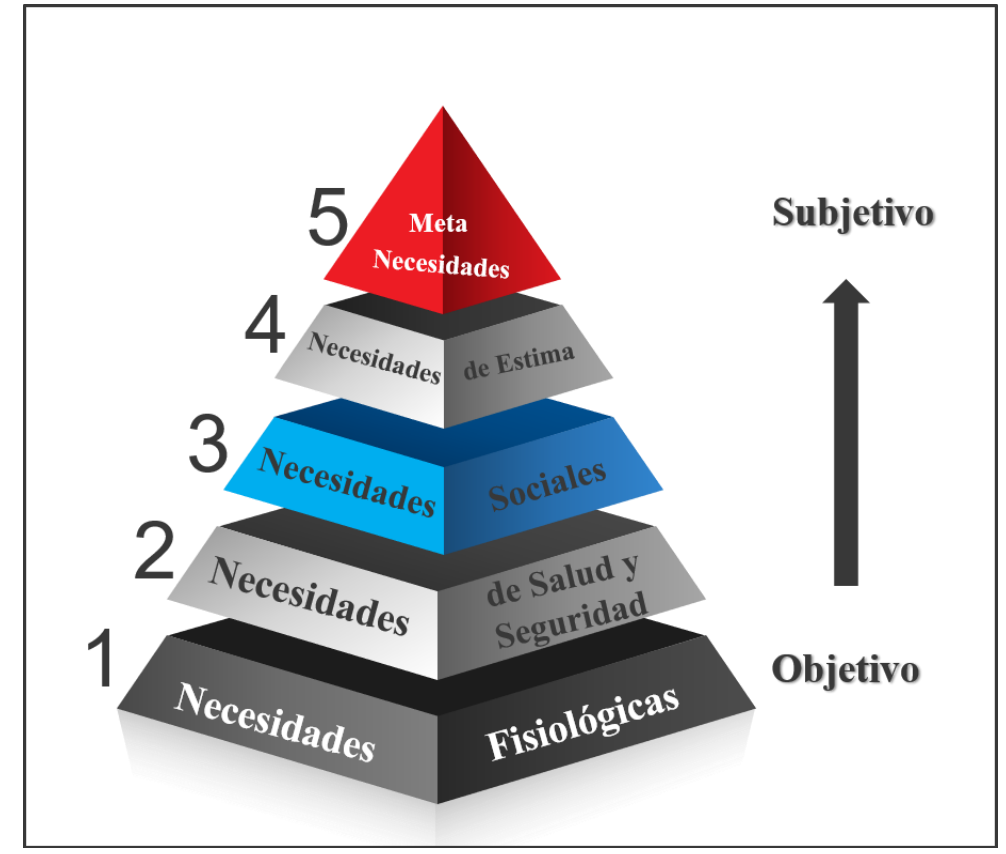

Figura 1. Pirámide de Maslow

Nota: Elaborado propia a partir de Maslow (1975).

Necesidades fisiológicas: representan las necesidades más básicas que sostiene componentes materiales para lograr satisfacción para disminuir factores que amenacen la supervivencia humana. Desde la mirada arquitectónico, se refiere a la infraestructura para realizar las actividades fisiológicas básicas dentro de un espacio.

Necesidades de salud y seguridad: se refiere a inclinarse hacia una vida segura, ordenada y cierta, que se aleje de cualquier situación de peligro y riesgo que atente con la integridad 
personal y familiar. En este sentido, cuando la persona tenga su vivienda, tiene que tener la capacidad de ofrecer seguridad y salubridad, sin arriesgar la vida de la población.

Necesidades sociales: es la voluntad de reconocer y ser reconocido por la sociedad sin restricciones sociales y culturales. Es sentirse arraigados en lugares e integrados en grupos y redes sociales, bajo un esquema de habitabilidad tipo urbano que posibilite la interacción e integración a la sociedad, propiciando lazos de amistad y asociación.

Necesidades de estima: la forma de satisfacer las necesidades varia en cada persona, como consecuencia, la persona puede o no sentir satisfacción. La relación existente entre los factores de satisfacción y las necesidades de las personas conlleva a obtener un grado bienestar del ser humano, las comunidades y la sociedad.

Metanecesidades: son aquellas situaciones de carácter psicológico e individualista que destaca virtudes, deseos, aspiraciones, potencialidades, entre otros; para lograr satisfacer el grado de bienestar. Por lo descrito, las viviendas son modificadas debido a que las necesidades de las personas van cambiando y por lo mismo se genera el fenómeno de apropiación.

Por lo establecido, se debe tomar en consideración a la población que lo habita, considerando los requerimientos y exigencias respecto a un determinado componente de necesidad tanto de individuos, grupos o incluso comunidades. Para que exista una necesidad, es necesario un satisfactor que tenga diferentes maneras de percepción y valoración hacia la sociedad, sobre todo del hábitat donde se desarrolla.

Actualmente, en Ecuador los proyectos de viviendas de interés social no logran integrar criterios de habitabilidad básicos, lo cual condiciona negativamente los niveles de confort y seguridad que acortan la vida útil, debido a que deben ser modificados por sus habitantes. En este escenario, Londoño (2016) expresa lo indispensable que resulta contar con indicadores de habitabilidad para viviendas de interés social (publicidad visual exterior, elementos culturales, estética y armonía inmobiliario, entre otros) que respondan a las necesidades básicas poblacional.

El Conjunto Habitacional 6 de diciembre - Etapa II-, ubicado en la ciudad de Chone, provincia de Manabí; es un claro ejemplo sobre la necesidad de desarrollar una herramienta tipo indicador para medir el nivel de habitabilidad en las viviendas de interés social en el Ecuador. De hecho, desde el momento que se entregaron las viviendas, se pudo evidenciar acabados inconclusos que tiene que ver con falta de enlucidos interiores y exteriores, recubrimientos de cerámica a nivel de piso, así como, ausencia en el recubrimiento a nivel del mesón de cocina. Asimismo, se realizaron trabajos adecuados y óptimos de impermeabilizado de la losa superior.

Estas situaciones ocasionaron consecuencias tales como, la generación de problemas a los propietarios que adquirieron las viviendas, quienes debían realizar una inversión extra para cubrir las carencias inconclusas al momento de su entrega. Por estas diferentes razones, es evidente la necesidad de plantear un instrumento que colabore con el Ministerio de Desarrollo Urbano y Vivienda (MIDUVI), con la intencionalidad de 
mejorar los indicadores de habitabilidad actual, y lograr obtener un cambio significativo acerca de la percepción en cuanto a la vivienda social en el Ecuador.

De aquí la pertinencia de plantear este tema de investigación como asunto de interés, actual y relevante; principalmente para todos los entes que participan en la concepción de estos programas de hábitat social, sobre todo, aquellos quienes se dedican al diseño y construcción de la vivienda. Para lograr este objetivo, se analizaron las herramientas relacionadas con la evaluación y medición de habitabilidad tanto en el contexto internacional, como dentro de lo conocido como el marco regulatorio y los procedimientos existentes en el contexto nacional. Se definieron los estándares sobre los cuales se debe medir la habitabilidad de acuerdo a las condiciones específicas en el Ecuador, generando una matriz que soporte el objetivo central y, a su vez, demostrar la aplicabilidad de la herramienta en un caso de estudio de vivienda social, en el Conjunto Habitacional 6 de diciembre - Etapa II-.

A manera de resumen, el concepto de habitabilidad a nivel mundial esta direccionada al confort, entendiéndose, así como un conjunto de condiciones ambientales, sin embargo, está limitada a las condiciones relativas en materia físico espacial, psicosocial y socioeconómica. Esta afirmación viene sustentada por lo expresado por la Organización Mundial de la Salud (2000) quien señala que el concepto involucra un adecuado desarrollo y una correcta prestación funcional. Como parte complementaria de esta investigación y siguiendo el cumplimiento de los objetivos pautados, seguidamente se detalla un análisis de diferentes contextos, acerca de cómo se considera la habitabilidad y como se mide la misma en Latinoamérica.

\section{Contexto en Chile}

En Chile, la habitabilidad se ha centrado como una concepción que describe los estándares de calidad de vida. Parafraseando al Instituto de la Vivienda (2004) es entendido como un alcance que está que se rige a la relación que existe entre el entorno y el hombre. A continuación, se especifica el índice de habitabilidad chileno:

\section{Tabla 1}

Índice de habitabilidad chileno

\begin{tabular}{clc}
\hline Grupo de infraestructura & $30.00 \%$ \\
\hline - & Hacinamiento & \\
- & Allegamiento \\
- & Espacio para ampliación & \\
- & Equipamiento comunitario & \\
\hline Grupo de servicios básicos & $20.00 \%$ \\
\hline - & Agua potable y alcantarillado & \\
- & Sistema de energía adecuado & \\
- & Entorno sin contaminación \\
- & Eliminación de basura \\
- & Seguridad contra incendio & \\
\hline
\end{tabular}




\begin{aligned} \hline Grupo de confort & $40.00 \% \\$\hline - & Iluminación interior y soleamiento \\ - & Aislamiento acústico \\ - & Aislamiento térmico \\ - & Ventilación en invierno y verano \\ - & Estanquidad de la envolvente \end{aligned}

\begin{tabular}{|c|c|}
\hline Parámetro transversal & $10.00 \%$ \\
\hline Hábitos saludables & \\
\hline Total & $=\quad 100.00 \%$ \\
\hline
\end{tabular}

Como se puede observar los grupos son variados pero homogéneos. Lo que se pretende es que sean incorporados como un todo, al momento de diseñar y construir soluciones habitacionales, bajo parámetros que realmente cubra las necesidades y expectativas, en este caso, de los futuros cohabitantes de la vivienda. Es necesario crear un programa que permita incorporar cada uno de estos grupos de manera sistemática y coherente al plano social chileno.

\section{Contexto en México}

Desde la perspectiva de la bioética en México, se concibe la habitabilidad de la vivienda en dimensiones donde se incorpora el barrio y la ciudad.

La dimensión humana está determinada por todo lo que el hombre adopta como propio, situaciones construidas y determinadas de forma automática, estableciendo objetos que asume como necesarios para su existencia. Dicha condición no sólo obedece a la posesión de elementos materiales u objetivos, sino a factores inmateriales e intangibles, como la estética o la belleza. Todas estas características, elementos o factores propios de la condición humana, son expresados tanto en la esfera pública, como en la privada; convirtiéndose en insumo básico y primordial para el desenvolvimiento del ser como persona sociable (Arendt, 2009).

La magnitud social mexicana, está formada por la familia, siendo el núcleo esencial de la sociedad, donde las viviendas deben ser estructuradas con base en sus actividades económicas, culturales, políticas y sociales. Al respecto Gazmuri (2013) concibe la familia como una categoría histórica matriarca, célula básica y esencial de la sociedad y su unidad económica, por supuesto desde una visión habitacional. La dimensión ambiental busca beneficiar a las personas y a toda la vida en el planeta, teniendo como objetivo fundamental el equilibrio ecológico de los ecosistemas. La vegetación es un elemento en el cual debe sustentarse la urbanización para proveer a los seres vivos de los beneficios de la naturaleza, evitar daños en el equilibrio natural (Rosabal y Torres, 2020 y American Planning Association, 2017).

Autores como Arboit et al. (2015) y Hasting (2015), sugieren que es requerida la inclusión de sistemas de diseño bioclimático urbano y arquitectónico al proceso del hábitat 
nacional, que permitan atenuar el impacto provocado por la creación y edificación de los asentamientos humanos en sectores vulnerables. La expansión desde una postura técnica de la habitabilidad, involucra todos los aspectos físicos, teóricos y materiales, así como las formas en que son implementados los dispositivos, tecnologías e infraestructura empleados en la construcción de las viviendas, de sus ambientes interior y exterior, de los barrios, comunidades y de las ciudades.

En la siguiente Tabla 2, se detallan las dimensiones con sus respectivos índices relevantes para conocer el estado o estatus de habitabilidad mexicano:

\section{Tabla 2}

Índice de habitabilidad mexicano

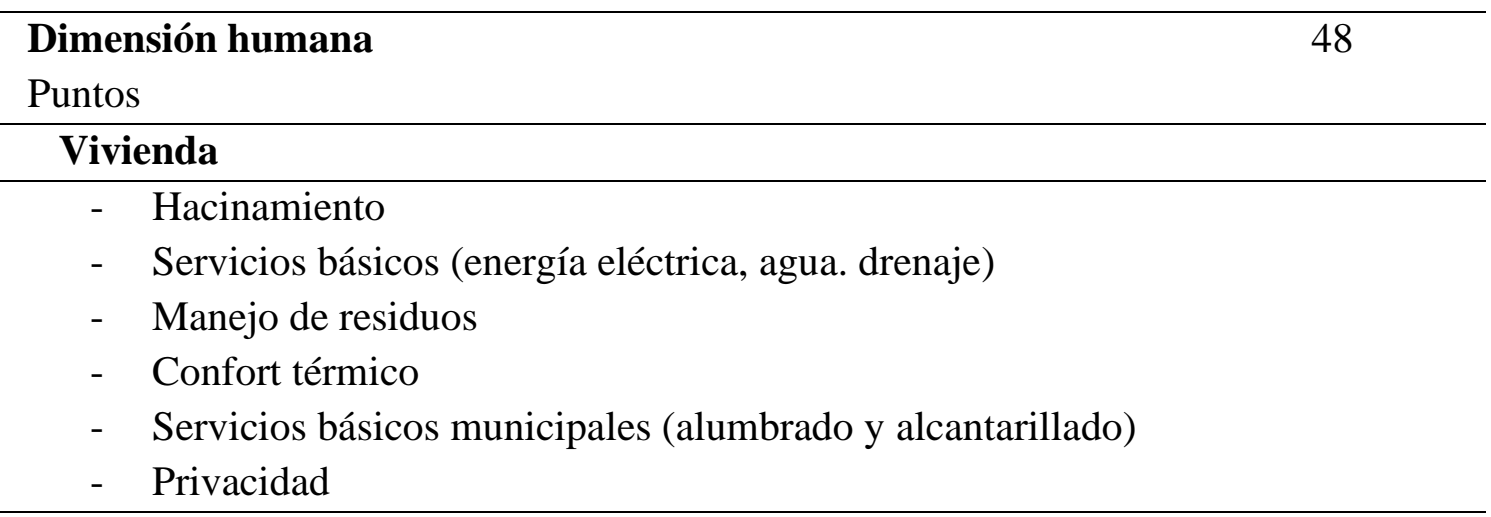

\section{Barrio}

- Educación

- Identidad local

\begin{aligned} & \hline \multicolumn{1}{l}{ Ciudad } \\ & \hline - Salud \\ & - Educación \\ & - Comercio y abastos \\ & - Sentido de identidad \\ & \hline Dimensión social 32 Puntos \\ & \hline Vivienda \\ & \hline - Interacción social \\ & - Sentido de apropiación y pertenencia de la vivienda y el entorno \\ & - Vinculación con el espacio semi-público \\ & - Integración al contexto vecinal próximo \\ & \hline\end{aligned}

\section{Barrio}

- Espacios de integración social

- Proximidad a paradas de transporte público

\section{Ciudad}

- Áreas de convivencia social

- Conectividad no motorizada con la acción urbanística

\begin{tabular}{lc}
\hline Dimensión ambiental & 36 Puntos \\
\hline Vivienda & \\
\hline
\end{tabular}

- Área verde al interior de la vivienda 
- Confort acústico

- Calidad de áreas verdes

- Proximidad y recolección de residuos urbanos

\section{Barrio}

- Integración de vegetación en el entorno

- Percepción de la calidad ambiental

\section{Ciudad}

- Superficie de área verde por habitante

- Calidad del aire

- Percepción espacial del verde urbano

\begin{aligned} & \hline Dimensión técnica 44 Puntos \\ & \hline Vivienda Uso de eco-tecnologías \\ & \hline - Espacio para ampliación \\ & - Calidad de los materiales \\ & - Iluminación \\ & - Diseño y dimensiones acordes a las necesidades \\ & - Banquetas y vialidades inmediatas \\ & - Percepción de la seguridad \\ & \hline\end{aligned}

\section{Barrio}

- Servicios municipales (alumbrado y alcantarillado)

- Superficie de vialidad para transporte peatonal

\section{Ciudad}

- Localización e interacción urbanística

- Morfología edificatoria

\begin{tabular}{ccc} 
Total & $=$ & 160 \\
Puntos & & \\
\hline
\end{tabular}

Fuente: D’Alencon, Justiniano, Márquez y Valderrama (2008)

En este caso el criterio de asignación de puntaje de acuerdo con la valoración de las variables que se presenten (satisfactorio, regular, deficiente o insatisfactorio), el cual otorga a una valoración satisfactoria 4 puntos, 3 a una adecuada, 2 a una regular, 1 a una deficiente y 0 puntos cuando se considera insatisfactoria la valoración (Cruz, 2018).

\section{Contexto en Colombia}

Mena (2011), describe que la habitabilidad requiere establecer condiciones y determinantes en una matriz para la medición de habitabilidad, con el fin de poder fijar una ponderación de cada acuerdo acorde a la misma definición, conformándose la siguiente matriz: 
Tabla 3

Matriz de ponderación

\begin{tabular}{lr}
\hline \multicolumn{1}{c}{ Condiciones } & \\
\cline { 1 - 2 } Ubicación & $1.30 \%$ \\
Diseño arquitectónico & $8.00 \%$ \\
Materiales & $1.50 \%$ \\
Mobiliario y dotación & $4.50 \%$ \\
Especificación física & $2.70 \%$ \\
Individuos & $10.00 \%$ \\
Hogares & $8.00 \%$ \\
Hacinamiento & $5.00 \%$ \\
Actividad & $4.00 \%$ \\
Nivel salarial & $8.00 \%$ \\
No. de individuos empleados & $7.00 \%$ \\
Persona dependiente & $10.00 \%$ \\
Desarrollo personal individual & $15.00 \%$ \\
Espacios de participación y desarrollo de liderazgos & $15.00 \%$ \\
\hline
\end{tabular}

Fuente: Vaca (2015, pp.104-107)

Para su calificación y ponderación de atributos por cada condición y determinante del nivel en el que se encuentra la vivienda, se califican de 25 a 100 puntos, valorando 25 como malo, 50 como regular, 75 como Bueno y 100 como excelente (Vaca, 2015).

\section{METODOLOGÍA}

Respecto a la metodología empleada en el estudio, se destaca que las mismas son consideradas como herramientas que sirven para la recolección de datos, soporte, formulación y medio para responder preguntas; que conllevan al planteamiento de conclusiones por medio de un análisis pragmático y teórico, aplicable a cualquier campo de estudio (Baena, 2017). Su naturaleza y diseño permite a los investigadores, ordenar las actividades y técnicas necesarias para adquirir información y datos relevantes, para soportar los resultados, la propuesta y conclusiones.

El presente artículo, se enmarca dentro del enfoque mixto, el cual Hernández et al. (2017) argumentan que "representan procesos sistemáticos, empíricos y críticos de investigación que implican la recolección y el análisis integrado de datos cuantitativos y cualitativos, para realizar inferencias y entender mejor el fenómeno que se estudia" (p. 22). Esta perspectiva de investigación, resalta la importancia de la metodología aplicada, en concordancia con el conjunto de procedimientos que permiten establecer acciones, para estructurar el trabajo, apoyados en procesos sistémicos que resultan de la recolección de datos. 
La investigación es aplicada, donde Valderrama (2014) afirma que busca conocer la íntima relación del problema sin perder su naturaleza, aplicando teorías que son necesarias para establecer principios generales con respecto a la idea o realidad. Al mismo tiempo, es descriptiva, exploratoria y bibliográfica-documental. Respecto al primero, permite describir las cualidades o características del objeto de estudio a través del instrumento de recolección de datos. Dichas características guardan especial interés en relacionar con los temas que permiten clasificar, organizar y detallar la problemática. Con relación al exploratorio, genera nuevos conocimientos hacia un tema novedoso, contribuyendo a la apertura de nuevos desarrollos en ejes temáticos centrales del estudio.

Por lo que se refiera al tipo bibliográfica-documental, el mismo tiene como propósito conocer, comparar, ampliar y profundizar diferentes teorías, conceptualización y criterios de diferentes autores. Se basa en estudios previos y en lecturas críticas (hermenéutica) de teorías referente al tema central, que sirvió de soporte para la aplicación y redacción de las conclusiones.

\section{RESULTADOS}

Definición de estándares sobre los cuales se debe medir la habitabilidad de la vivienda social de acuerdo a las condiciones específicas en el Ecuador.

Una vez que se analizaron las herramientas que se utilizan para medir la habitabilidad en el contexto internacional, así como también las regulaciones y procedimientos que existen para medir la habitabilidad en el contexto nacional, se realizó un estudio cualitativo de campo mediante la observación y entrevista, para la obtención de la información y, así, definir los parámetros de habitabilidad ajustados a la realidad de los investigadores.

Asimismo, se realizó un análisis comparativo, entre las herramientas utilizadas en otros contextos; para medir la habitabilidad y poder generar nuestra propuesta sobre la herramienta adecuada para la medición de habitabilidad en viviendas en el Ecuador en materia físico espacial, psicosocial y socioeconómico. Se tomó como referencia, la matriz de evaluación de los índices de habitabilidad propuesta por Alecon et al. (2010), tal como se describe en la tabla 4.

Variable dependiente: Modificaciones de la vivienda Variable independiente: Calidad de la vivienda entregada

\begin{tabular}{llll}
\hline & MATRIZ PARA LA & & PROPUESTA DE \\
MATRIZ DE & MEDICIÓN DE & MATRIZ PARA LA & HERRAMIENTA \\
EVALUACIÓN & HABITABILIDAD & MEDICIÓN DE & PARA LA \\
DE LOS ÍNDICES & MEDIANTE & HABITABILIDAD & MEDICIÓN DE \\
DE & DIMENSIONES & MEDIANTE & HABITABILIDAD \\
HABITABILIDAD & (VIVIENDA, BARRIO Y & CONDICIONES & EN VIVIENDAS \\
& CIUDAD) & & EN EL \\
CONTEXTO - & CONTEXTO - MÉXICO & CONTEXTO - & ECUADOR \\
CHILE & & COLOMBIA &
\end{tabular}




\begin{tabular}{|c|c|c|c|}
\hline Grupos & $\begin{array}{l}\text { Dimensiones (vivienda, } \\
\text { barrio y ciudad) }\end{array}$ & $\begin{array}{l}\text { Condiciones de la } \\
\text { vivienda }\end{array}$ & $\begin{array}{l}\text { Componentes de la } \\
\text { vivienda }\end{array}$ \\
\hline \multirow{19}{*}{$\begin{array}{l}\text { Grupo de } \\
\text { infraestructura } \\
\text { - Hacinamiento } \\
\text { - Allegamiento } \\
\text { - Espacio para } \\
\text { ampliación } \\
\text { - Equipamiento } \\
\text { comunitario }\end{array}$} & $\begin{array}{l}\text { Dimensión humana } \\
\text { Vivienda } \\
\text { - Hacinamiento } \\
\text { - Servicios básicos (energía }\end{array}$ & $\begin{array}{l}\text { Condiciones: } \\
\text { - Ubicación } \\
\text { - Diseño arquitectónico } \\
\text { - Materiales }\end{array}$ & \\
\hline & eléctrica, agua. drenaje) & - Mobiliario y dotación & 1. Infraestructura \\
\hline & - Manejo de residuos & - Especificación física & 1.1. Tipo de \\
\hline & - Servicios básicos & - Hogares & 12.1 .2 \\
\hline & municipales (alumbrado y & - Hacinamiento & Hacinamiento \\
\hline & alcantarillado) & - Actividad & 1.3. Allegamiento \\
\hline & - Privacidad & - Nivel salarial & 1.4. Espacio para \\
\hline & Barrio & - No. De individuos & ampliación \\
\hline & - Educación & empleados & 1.5. Acabados \\
\hline & - Identidad local & - Persona dependiente & exteriores e \\
\hline & Ciudad & - Desarrollo personal & interiores \\
\hline & - Salud & individual & \\
\hline & - Educación & - Espacios de & \\
\hline & - Comercio y abastos & participación y & \\
\hline & - Sentido de identidad & desarrollo de & \\
\hline & Dimensión social & liderazgos & \\
\hline & Vivienda & & \\
\hline & - Interacción social & & \\
\hline & - Sentido de apropiación y & & \\
\hline \multirow{2}{*}{$\begin{array}{l}\text { Grupo de servicios } \\
\text { básicos }\end{array}$} & pertenencia de la vivienda y & & \\
\hline & el entorno & & 2. Servicios básicos \\
\hline \multirow{4}{*}{$\begin{array}{l}\text { - Agua potable y } \\
\text { alcantarillado } \\
\text { - Sistema de energía } \\
\text { adecuado }\end{array}$} & - Vinculación con el espacio & & 2.1. Agua \\
\hline & semi-público & & potable y \\
\hline & - Integración al contexto & & alcantarillado \\
\hline & vecinal próximo & & 2.2. Sistema de \\
\hline \multirow{9}{*}{$\begin{array}{l}\text { - Entorno sin } \\
\text { contaminación } \\
\text { - Eliminación de } \\
\text { basura } \\
\text { - Seguridad contra } \\
\text { incendio }\end{array}$} & Barrio & & energía adecuado \\
\hline & - Espacios de integración & & 2.3. Entorno sin \\
\hline & social & & contaminación \\
\hline & - Proximidad a paradas de & & 2.4. Seguridad \\
\hline & transporte público & & contra incendio \\
\hline & Ciudad & & \\
\hline & - Áreas de convivencia social & & \\
\hline & - Conectividad no & & \\
\hline & $\begin{array}{l}\text { motorizada con la acción } \\
\text { urbanística }\end{array}$ & & \\
\hline \multirow{2}{*}{$\begin{array}{l}\text { Grupo de confort } \\
\text { - Iluminación }\end{array}$} & Dimensión ambiental & & 3. Confort \\
\hline & Vivienda & & 3.1. Iluminación \\
\hline
\end{tabular}




interior y
soleamiento
- Aislamiento
acústico
- Aislamiento
térmico
- Ventilación en
invierno y verano
- Estanquidad de la
envolvente

Parámetro

transversal

- Hábitos saludables
- Área verde al interior de la

vivienda

- Confort acústico

- Calidad de áreas verdes

- Proximidad y recolección de residuos urbanos

Barrio

- Integración de vegetación

en el entorno

- Percepción de la calidad

ambiental

Ciudad

- Superficie de área verde

por habitante

- Calidad del aire

- Percepción espacial del

verde urbano

\section{Dimensión técnica}

\section{Vivienda}

- Uso de eco-tecnologías

- Espacio para ampliación

- Calidad de los materiales

- Iluminación

- Diseño y dimensiones

acordes a las necesidades

- Banquetas y vialidades

inmediatas

- Percepción de la seguridad

\section{Barrio}

- Servicios municipales

(alumbrado y alcantarillado)

- Superficie de vialidad para

transporte peatonal

\section{Ciudad}

- Localización e interacción

urbanística

- Morfología edificatoria interior y

soleamiento

3.2 .

Aprovechamiento de la ventilación

3.3.

Funcionabilidad interior

3.4. Aislamiento acústico

3.5. Aislamiento térmico
4. Hábitos saludables 4.1. Hábitos saludables

Fuente: D’Alencon, Justiniano, Márquez y Valderrama (2008)

Así se obtuvieron cuatro grupos por componentes, según la afinidad conceptual del problema que se representa. Posteriormente, se analizaron los parámetros descritos para cada uno de ellos, estableciendo niveles mínimos de habitabilidad, con apego a las 
regulaciones vigentes y en concordancia con una percepción aceptable de la vivienda, tal como se describe a continuación (ver Tabla 5) con su respectivo ponderado:

\section{Tabla 4}

Grupo de componentes por afinidad

\begin{tabular}{ll}
\hline \multicolumn{2}{l}{ Componentes: } \\
\hline 1. Infraestructura & $35.00 \%$ \\
\hline 1.1. Tipo de estructura \\
1.2. Hacinamiento \\
1.3. Allegamiento \\
1.4. Espacio para ampliación \\
1.5. Acabados exteriores e interiores \\
2. Servicios básicos $30.00 \%$
\end{tabular}

2.1. Agua potable y alcantarillado

2.2. Sistema de energía adecuado

2.3. Entorno sin contaminación

2.4. Seguridad contra incendio

3. Confort

$30.00 \%$

3.1. Iluminación interior y soleamiento

3.2. Aprovechamiento de la ventilación

3.3. Funcionabilidad interior

3.4. Aislamiento acústico

3.5. Aislamiento térmico

4. Hábitos saludables

$5.00 \%$

$\begin{array}{ll}\text { 4.1. Hábitos saludables } & \\ \text { Total } & =\mathbf{1 0 0 . 0 0 \%}\end{array}$

Fuente: D’Alencon, Justiniano, Márquez y Valderrama (2008)

En la Tabla 6, se muestra la descripción de cada los niveles del 1 al 5; mismos que categorizan cada parámetro propio de cada componente. Esto se hace con el objetivo de calcular mediante una ponderación el desempeño de cada uno de ellos, y obtener nuestros propios resultados.

\section{Tabla 5}

Rúbrica de evaluación de habitabilidad por componentes

\begin{tabular}{|c|c|c|c|c|c|}
\hline $\begin{array}{c}\text { DESCRIPCIÓN DE } \\
\text { LOS }\end{array}$ & MUY BUENO & BUENO & MÍNIMO & DEFICIENTE & MALO \\
\hline $\begin{array}{c}\text { COMPONENTES } \\
\text { PARÁMETROS }\end{array}$ & 5 & 4 & 3 & 2 & 1 \\
\hline \multicolumn{6}{|c|}{ 1.- INFRAESTRUCTURA (35\%) } \\
\hline $\begin{array}{l}\text { Tipo de } \\
\text { estructura }\end{array}$ & $\begin{array}{c}\text { Cuando se diseña la } \\
\text { cimentación con un sistema } \\
\text { que está por encima de los } \\
\text { parámetros mínimos }\end{array}$ & $\begin{array}{l}\text { Cuando se diseña la } \\
\text { cimentación con un } \\
\text { sistema que está por } \\
\text { encima de los }\end{array}$ & $\begin{array}{l}\text { Cuando se diseña la } \\
\text { cimentación de } \\
\text { acuerdo a los } \\
\text { parámetros }\end{array}$ & $\begin{array}{l}\text { Cuando se cumple } \\
\text { una de las dos, o se } \\
\text { diseña la cimentación } \\
\text { de acuerdo a los }\end{array}$ & $\begin{array}{l}\text { Cuando no diseña la } \\
\text { cimentación de } \\
\text { acuerdo a los } \\
\text { parámetros mínimos }\end{array}$ \\
\hline
\end{tabular}




\begin{tabular}{|c|c|c|}
\hline & & $\begin{array}{l}\text { obtenidos por el estudio de } \\
\text { suelos realizado en campo } \\
\text { y se considera parámetros } \\
\text { externos que están por } \\
\text { encima de las normativas } \\
\text { vigentes. }\end{array}$ \\
\hline 1.2 & Hacinamiento & $\begin{array}{l}\text { Cuatro dormitorios para la } \\
\text { familia ( } 5 \text { personas), sala, } \\
\text { comedor, cocina, } \\
\text { lavandería, dos baños } \\
\text { completos y un baño social }\end{array}$ \\
\hline 1.3 & Allegamiento & $\begin{array}{l}\text { Una vivienda } 126 \mathrm{~m} 2 \text { - } \\
\text { Donde el terreno sea } \\
\text { mínimo de } 144 \mathrm{~m} 2\end{array}$ \\
\hline 1.4 & $\begin{array}{l}\text { Espacio para } \\
\text { ampliación }\end{array}$ & $\begin{array}{c}\text { Existe ampliación en planta } \\
\text { hacia el área posterior y los } \\
\text { dos costados de la vivienda, } \\
\text { así mismo en altura permite } \\
\text { un nivel más, manteniendo } \\
\text { retiros laterales y } \\
\text { posteriores. }\end{array}$ \\
\hline 1.5 & $\begin{array}{l}\text { Acabados } \\
\text { exteriores e } \\
\text { interiores }\end{array}$ & $\begin{array}{l}\text { Se consideran acabados } \\
\text { completos en la } \\
\text { mampostería a nivel de } \\
\text { pintura o cualquier tipo de } \\
\text { recubrimiento de la misma } \\
\text { forma recubrimientos en } \\
\text { pisos y mesones, acabados } \\
\text { en interiores de la vivienda } \\
\text { con diseños }\end{array}$ \\
\hline
\end{tabular}

\section{2.- SERVICIOS BÁSICOS (30\%)}

Agua potable y
alcantarillado

Existen servicios de agua potable y alcantarillados habilitados incluyendo un plan de mantenimiento que dé respuesta inmediata a un problema

Alumbrado eléctrico soterrado, con factores de

2.2 Sistema de iluminación que sobrepasan energía adecuado lo necesario incluyendo la iluminación de áreas aledañas a las viviendas

$2.3 \begin{gathered}\text { Entorno sin } \\ \text { contaminación }\end{gathered}$

Al menos cinco veces por semana se recolectan los desechos contaminantes

Existe hidrantes o bocas de fuego colocados

Seguridad contra estratégicamente en caso de incendio

\section{3.- CONFORT (30\%) Iluminación 3.1 interior $\mathrm{y}$ soleamiento \\ La vivienda presenta iluminación natural en sus ambientes (sala, comedor,} respectiva señalética de uso y evacuación en caso de emergencia. parámetros mínimos obtenidos por el estudio de suelos realizado en campo y en apego a las normativas vigentes.

Tres dormitorios para la familia (5 personas), sala, comedor, cocina, lavandería, dos baños completos y un baño social

Una vivienda $118 \mathrm{~m} 2$ Donde el terreno sea mínimo de 144m2

Existe ampliación en planta hacia el área posterior y los dos costados de la vivienda, así mismo en altura permite un nivel más.

Se consideran acabados completos en la mampostería a nivel de pintura o cualquier tipo de recubrimiento, de la misma forma

recubrimientos en pisos y mesones.

Existen servicios de agua potable $\mathrm{y}$ alcantarillados habilitados incluyendo un plan de diagnóstico y mantenimiento anualmente

Alumbrado eléctrico soterrado, con factores de iluminación que sobrepasan lo necesario

Al menos cuatro veces por semana se recolectan los desechos contaminantes

Existe hidrantes o bocas de fuego colocados estratégicamente en caso de incendio con su respectiva señalética de uso y evacuación en caso de emergencia.
La vivienda presenta iluminación natural en sus ambientes (sala,
Existen servicios de agua potable y alcantarillados habilitados

Alumbrado

eléctrico soterrado ajustado a la iluminación necesaria

Al menos tres veces por semana se recolectan los desechos contaminantes

Existe hidrantes o bocas de fuego colocados

parámetros mínimos

obtenidos por el

obtenidos por el

estudio de suelos

realizado en campo, o

se trabaja en apego a

las normativas vigentes.

Dos dormitorios para la familia (5 personas), sala, comedor, cocina,

lavandería y un baño completo

Una vivienda $36 \mathrm{~m} 2$ Donde el terreno sea menos de $120 \mathrm{~m} 2$

estudio de suelos

realizado en campo y

tampoco en apego a

las normativas vigentes.

Un solo dormitorio para la familia (5 personas), sala, comedor, cocina, lavandería y un baño completo

Una vivienda $27 \mathrm{~m} 2$ Donde el terreno sea menos de $120 \mathrm{~m} 2$

Solo existe ampliación en planta hacia el área posterior de la vivienda y no en altura

No existe ampliación en planta ni en elevación

No se consideran

No se consideran recubrimientos en pisos y mesones.

enlucidos en paredes tampoco recubrimientos en pisos y mesones.

Existe solo un servicio habilitado ya sea de agua potable o de alcantarillado

No existe ningún servicio de agua potable, alcantarillado e hidrantes

Existe alumbrado público aéreo deficiente (no hay adecuada

iluminación)

Dos veces por semana se recolectan los desechos contaminantes estratégicamente en caso de incendio

Señalética de evacuación en caso de incendios

No existe alumbrado público

Una vez por semana se recolectan los desechos contaminantes

No existe ningún equipo de prevención, señalética de evacuación o SCI (Sistema Contra Incendio)

La vivienda presenta iluminación natural
La vivienda solo cumple con varios de

La vivienda no presenta iluminación natural en sus 


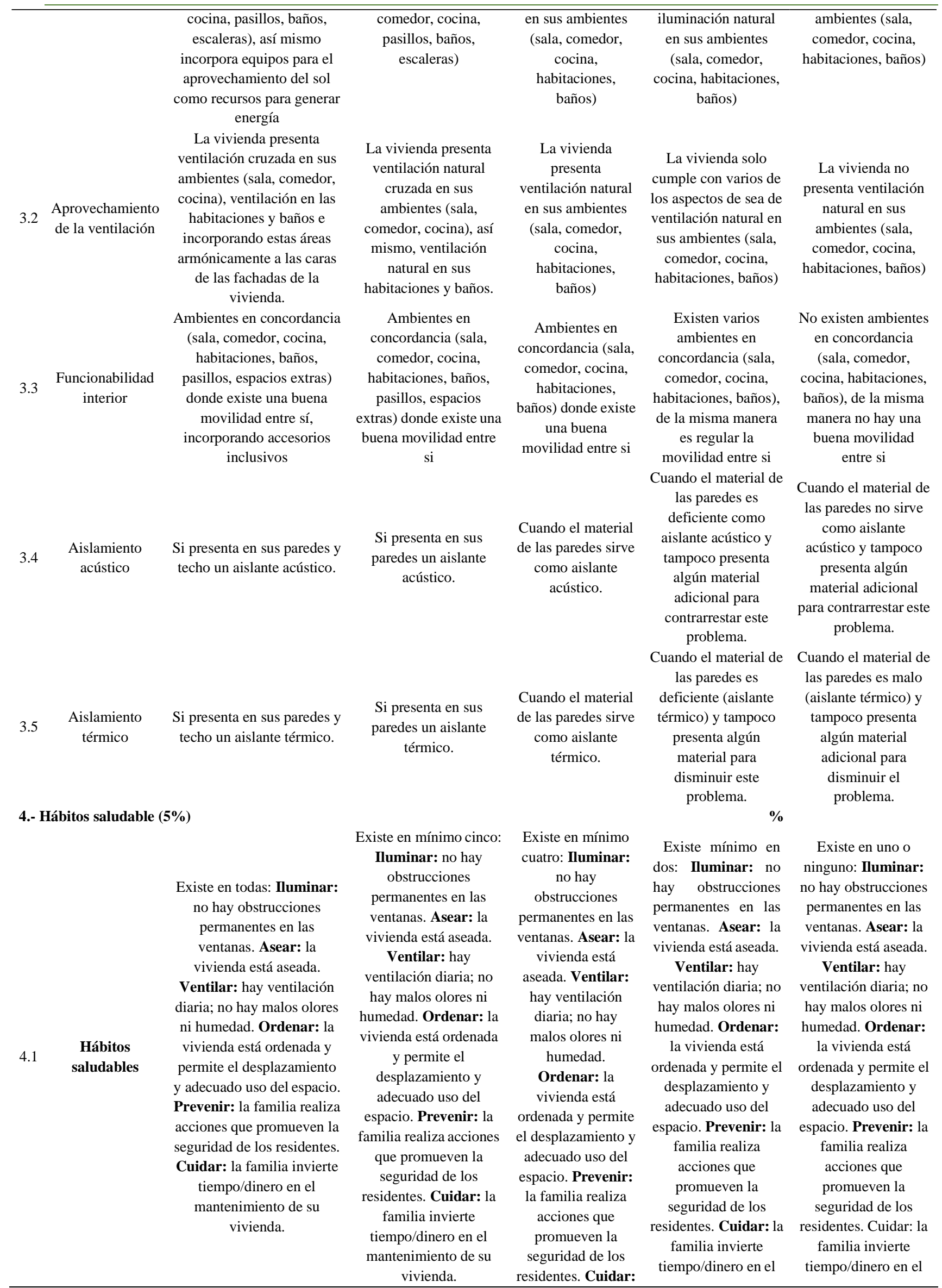




\section{Aplicabilidad de la herramienta propuesta en el caso de estudio "conjunto habitacional 6 de diciembre -Etapa II-.}

Se escogió el Conjunto Habitacional 6 de diciembre - Etapa II - como caso de estudio, para poder aplicar nuestra matriz para evaluar la habitabilidad. El proyecto se encuentra ubicado al suroeste de la ciudad de Chone, asentado a las orillas del Río Chone en las coordenadas $9922152 \mathrm{~N}$; 598841E, sobre un área de $13,127.40 \mathrm{~m}^{2}$ en la provincia de Manabí. Allí nace por la necesidad de dotar de viviendas a las personas de bajos recursos económicos quienes aplican a un crédito en cualquier entidad bancaria que acrediten por un valor $\$ 8,500.00$, y como incentivo el propietario de la vivienda recibe mediante el MIDUVI, un bono de vivienda por un valor de $\$ 5,000.00$, que le brinda el estado ecuatoriano. Esto significa que el costo total de la vivienda es de $\$ 13,500.00$.

El proyecto de vivienda de interés social empezó su construcción en octubre del 2010 y finalizó su construcción en diciembre del 2011. El alcance del proyecto investigado, se puede ver en la Figura 2.

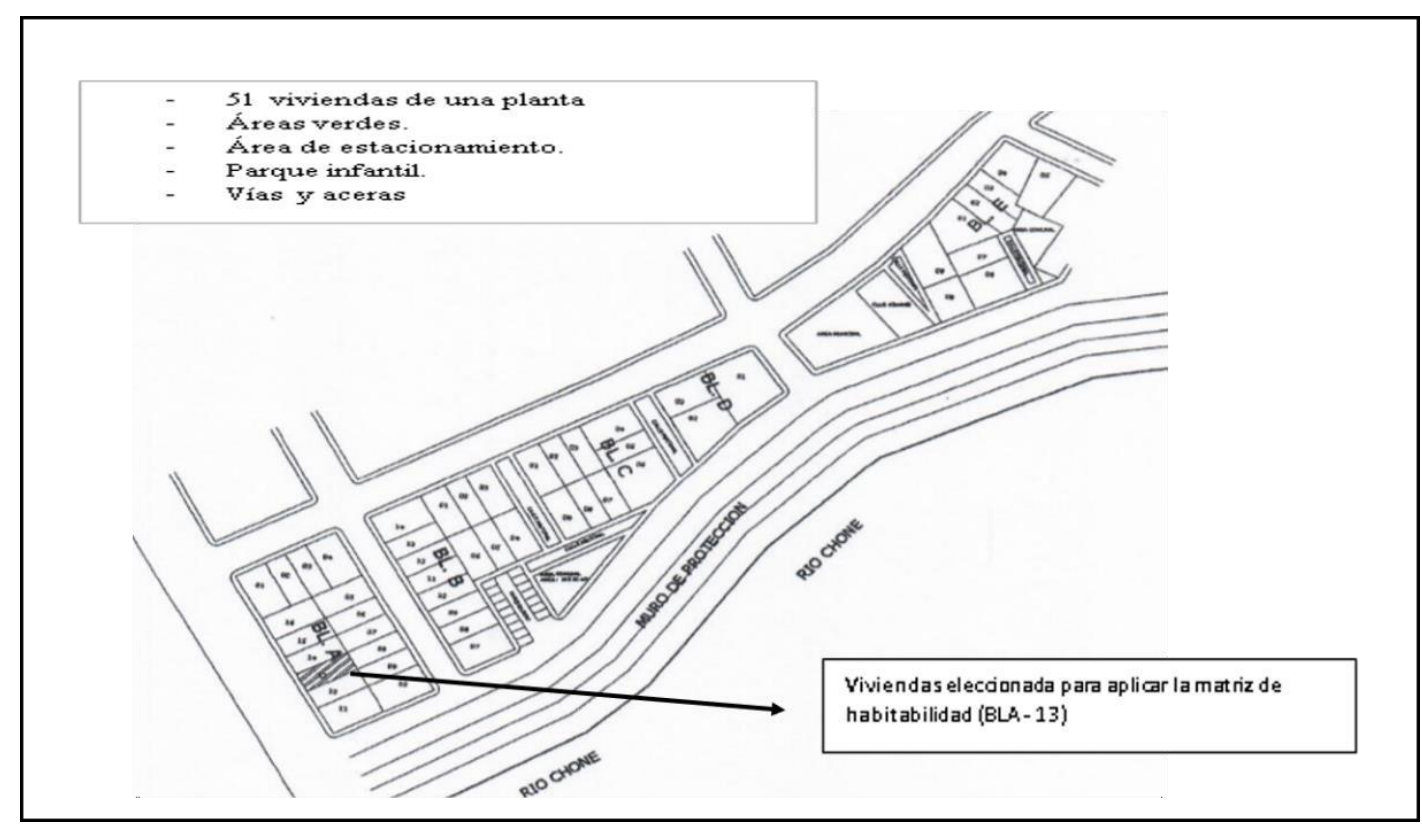

Figura 2. Conjunto Habitacional 6 de diciembre-Etapa IIFuente: GADM - Chone, provincia de Manabí.

Se escogió una vivienda medianera, la vivienda se encuentra implantada en un lote tipo de $90.00 \mathrm{~m}^{2}$ (6.00 x 15.00mts), mismo que se muestra en la Figura 3. 


\section{Retiro:}

$2.50 \times 6.00 \mathrm{~m}$

Vivienda de una planta:

$6.00 \times 6.00 \mathrm{~m}$

Patio:

Área total:

$6.50 \times 6.00 \mathrm{~m}$

$90.00 \mathrm{~m}^{2}$

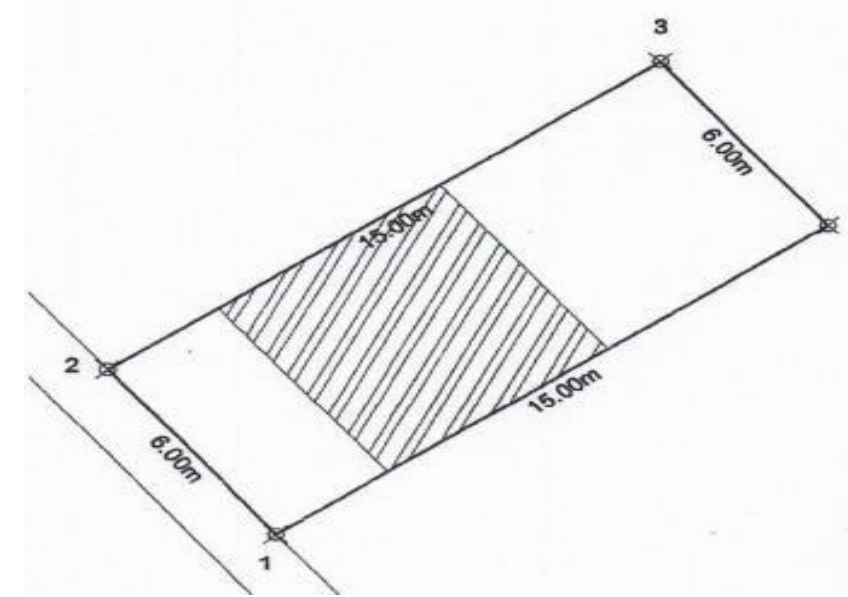

Figura 3. Lote tipo Conjunto Habitacional 6 de diciembre-Etapa IIFuente: GADM - Chone, provincia de Manabí.

La distribución con las que cuentan las viviendas de 36m2 (6.00x6.00mt), están descritas en la Figura 4.

- Sala, comedor, cocina (un solo ambiente)

- 2 habitaciones

- 1 baño completo

- Lavandería posterior

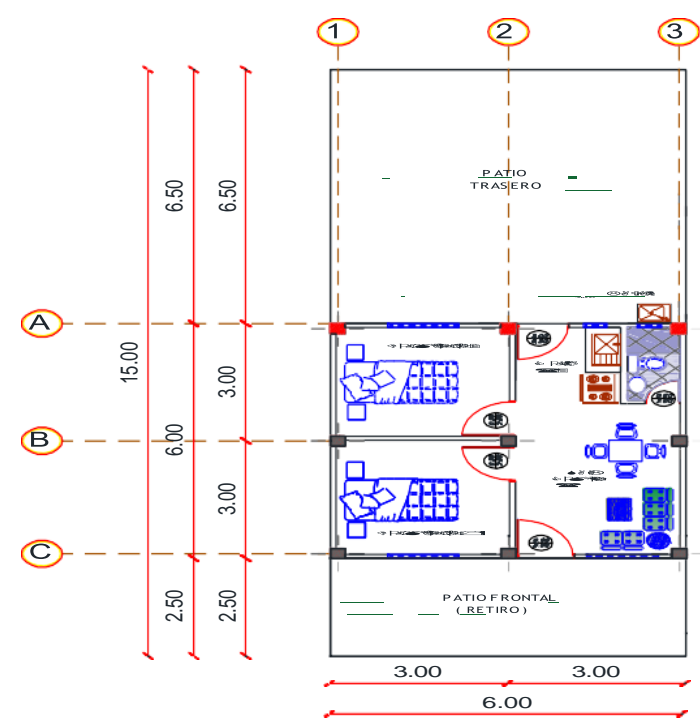


Figura 4. Distribución de la vivienda BLA-13, Conjunto Habitacional 6 de diciembreEtapa II-

Fuente: GADM - Chone, provincia de Manabí.

Así mismo se observa la fachada frontal de la vivienda BLA-13 escogía para ser evaluada, en la Figura 5.

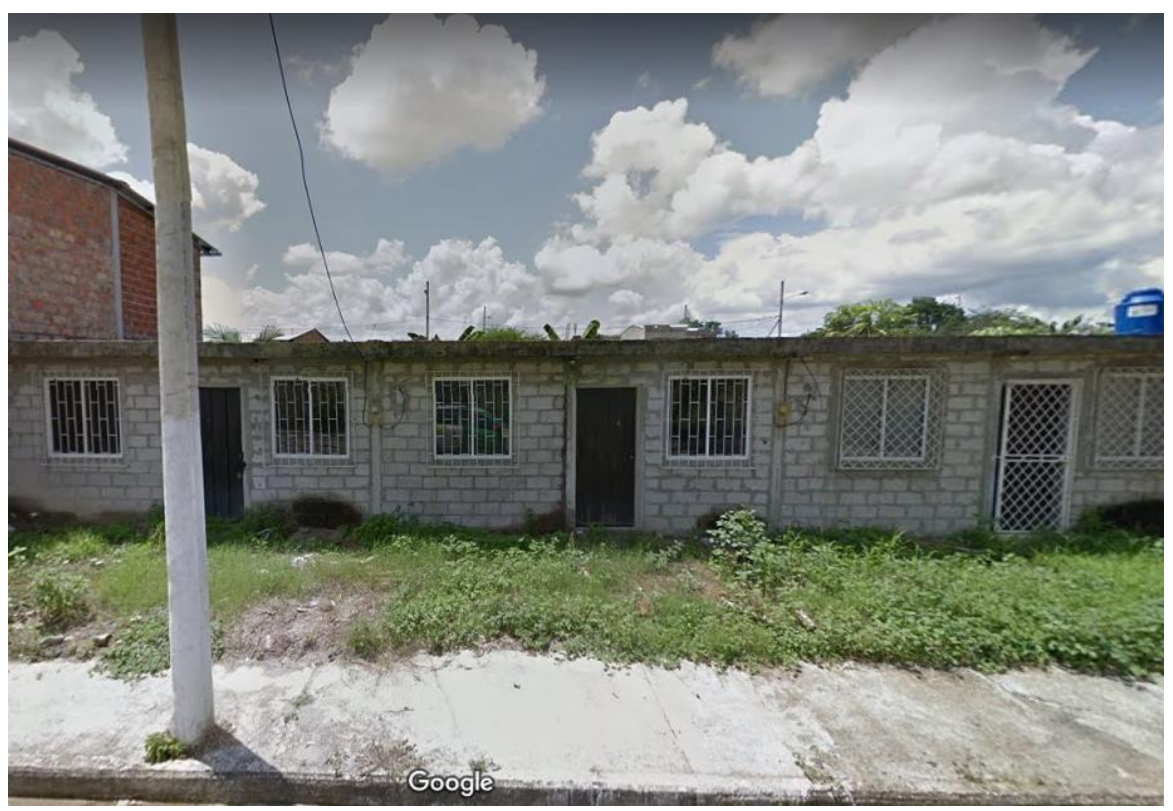

Figura 5. Fachada frontal de la vivienda objeto de estudio (BLA - 13)

Fuente: Elaboración propia

Las viviendas son adosadas en ambos costados, su acabado es en mampostería debloque visto, losa fundida monolíticamente en el bloque de las viviendas, en el nivel superior con progresividad hacia una segunda planta y también hacia el patio posterior, sin incluir el cerramiento perimetral del lote, el piso se encuentra en acabado gris sin recubrimientos de cerámica u otro elemento, ventanas de aluminio y vidrio, puerta principal y posterior metálicas, puertas internas de madera, con este antecedente partiremos para evaluar este estudio de caso y obtener nuestras propias consideraciones.

\section{Análisis de los parámetros de habitabilidad}

Para poder aplicar la matriz de habitabilidad a proponer, se escogió la vivienda \# 13 del Bloque - A. De esta forma, se procedió a analizar los pormenores que conforma dicha casa, para que formara parte del estudio planteado, y obtener los siguientes resultados. La vivienda evaluada BLA-13 presenta diversas adversidades y carencias, que parten del análisis previo de cada componente, que se detalla a continuación:

En el componente de la infraestructura, la vivienda no contó con un estudio de suelos realizado en sitio, existían dos habitaciones de $36 \mathrm{~m}^{2}$ para una familia de 5 personas, permite ampliación en elevación y hacia atrás, no cuenta con recubrimientos en piso, mesones y tampoco enlucidos. En el componente de servicios básicos, solo cuenta con servicio de agua potable, el sistema de energía proporcionado es aéreo, en lo que respecta 
a recolección de desechos existe una planificación de dos recolecciones por semana, así mismo cuenta con bocas de fuego en caso de una emergencia de incendios ubicadas en las esquinas.

En el componente de confort, la iluminación como la ventilación son deficientes, esto obedece a que la vivienda es adosada en ambos costados con excepción de las esquineras. En lo que respecta a la funcionabilidad interior, debido a contar con un área de $36 \mathrm{~m}^{2}$, no existen privatización de espacios por ser una vivienda construida con bloque no presenta aislamientos térmicos y acústicos. En el componente de hábitos saludables, el aseo de la vivienda es semanal, así mismo, no se encuentra ordenada.

En la tabla 7, se muestra la matriz para medir la habitabilidad de las viviendas en el Ecuador, aplicada en el caso de estudio: Conjunto Habitacional 6 de diciembre -Etapa II-.

\section{Tabla 6}

Matriz para medir la habitabilidad de las viviendas en el Ecuador, aplicada en el caso de estudio: Conjunto Habitacional 6 de diciembre, (Etapa II)

\section{DESCRIPCIÓN DE LOS COMPONENTES}

\section{$5 \quad 4 \quad 3 \quad 2$}

MUY BUENO MÍNIMO DEFICIENTE MALO

PARÁMETROS

\section{BUENO}

4

3

1.- INFRAESTRUCTURA (35\%)

$12.60 \%$

1.1 Tipo de estructura

$\mathbf{X}$

1.2 Hacinamiento

$\mathbf{X}$

1.3 Allegamiento

$\mathbf{X}$

1.4 Espacio

para

ampliación

1.5 Acabados exteriores e

$\mathbf{X}$ interiores

\section{2.- SERVICIOS BÁSICOS (30\%)}

$13.50 \%$

2.1 Agua potable y alcantarillado

2.2 Sistema de energía adecuado

2.3 Entorno sin contaminación

2.4 Seguridad contra incendio

3.- CONFORT (30\%) 
3.1 Iluminación interior y soleamiento

3.2 Aprovechamiento de $\mathbf{X}$ la ventilación

3.3 Funcionabilidad $\mathbf{X}$ interior

3.4 Aislamiento acústico $\mathbf{X}$

3.5 Aislamiento térmico

4.1 Hábitos saludables

$\mathbf{X}$

HABITABILIDAD

TOTAL

37.70

Nota: Elaboración propia

De la misma manera se muestra la tabla 8 de resumen de resultados de habitabilidad, obtenidos en el caso de estudio: Conjunto Habitacional 6 de diciembre-Etapa II-

\section{Tabla 7}

Resumen de resultados de habitabilidad obtenidos en el caso de estudio: Conjunto Habitacional 6 de diciembre-Etapa II-

\begin{tabular}{cccccc}
\hline & MUY & BUENO & MÍNIMO & DEFICIENTE & MALO \\
DESCRIPCIÓN & BUENO & & & & \\
& $\mathbf{9 0 -}$ & $\mathbf{7 0 \% -}$ & $\mathbf{5 0 \%}-$ & $\mathbf{3 0 \%}-\mathbf{5 0 \%}$ & $\mathbf{0 - 3 0 \%}$ \\
& $\mathbf{1 0 0 \%}$ & $\mathbf{9 0 \%}$ & $\mathbf{7 0 \%}$ & & \\
\hline
\end{tabular}

Elaboración propia

\section{CONCLUSIONES}

Se estudiaron diferentes herramientas para medir habitabilidad, tomando como referencia diferentes contextos Latinoamericanos como: Chile, México y Colombia; en las cuales se definieron parámetros comunes que se utilizaron como base para definir la matriz de habitabilidad el hacinamiento, confort térmico, confort acústico, iluminación, ventilación, materiales de la vivienda, servicios básicos y el entorno de la vivienda.

Una vez estudiado el marco regulatorio en el Ecuador se concluye que los conceptos de habitabilidad se encuentran dispersos y no contribuyen como una herramienta eficaz para mejorar las condiciones de habitabilidad en la vivienda social. Actualmente se ha venido dando en diversos programas desde un enfoque cuantitativo y no cualitativo. 
Se definieron cuatro componentes a ser incluidos en la matriz de habitabilidad, los cuales se describen como: infraestructura, servicios básicos, confort y hábitos saludables; a partir de los cuales se desagregan parámetros mínimos para cada uno de ellos y, a su vez, se insertan los parámetros comunes analizadas en el contexto internacional.

Se generó la matriz de habitabilidad para vivienda tipo social en el Ecuador, la cual se compone de cuatro componentes y 15 parámetros que consideran los aspectos relacionados a lo físico espacial, psicosocial, térmico, acústico, lumínico y seguridad. Los factores de ponderación por componentes son los siguientes: infraestructura $35 \%$, servicios básicos $30 \%$, confort $30 \%$ y hábitos saludables $5 \%$, lo que otorga un total del $100 \%$.

La aplicación de la matriz de habitabilidad propuesta, permite obtener un resultado general a partir de la puntuación obtenida, la cual define cinco niveles. Puntuación entre $90 \%-100 \%$, muy bueno; entre $70 \%-90 \%$, bueno; entre $50 \%-70 \%$, mínimo; entre $30 \%$ - $50 \%$, deficiente y menor de $30 \%$, malo.

Mediante la matriz propuesta para medir la habitabilidad, se evaluó el caso de estudio Conjunto Habitacional 6 de diciembre-Etapa II-, escogiendo la vivienda más desfavorable (BLA - 13, medianera). La valoración obtenida en el componente de infraestructura fue del $12.60 \%$ de un $35 \%$ posible, en el componente servicios básicos fue del $13.50 \%$ de un $30 \%$ posible, en lo que respecta al componente confort se obtuvo el $9.60 \%$ de un $30 \%$ posible, y en el componente hábitos saludables se obtuvo el $2.00 \%$ de un 5\% máximo. Al hacer un análisis del comportamiento de los componentes encontramos que los servicios básicos es el mejor puntuado con un $45 \%$ de ponderación, mientras que el más deficiente fue el confort que solo alcanzó el 32\%.

Como resultado final de esta evaluación, se obtuvo el $37.70 \%$ que, a su vez, la categoriza como una vivienda deficiente. Este resultado, obedece al sinnúmero de carencias de parámetros de habitabilidad que existen.

\section{RECOMENDACIONES}

Se recomienda la aplicación de la matriz de habitabilidad propuesta en esta investigación, como herramienta base para aquellas instituciones relacionadas con el tema de la habitabilidad, previo a la entrega de proyectos de viviendas ya sea en el ámbito gubernamental (MIDUVI) o particular, logrando de esta forma, poder involucrar las necesidades básicas. Asimismo, es importante mantener un sistema de retroalimentación para ajustar adecuadamente la matriz, tomando en consideración cada zona o realidad del Ecuador.

\section{REFERENCIAS BIBLIOGRÁFICAS}

Alecon, R., Justiniano, C., Márquez, F., y Valderrama, C. (2010). Parámetros y estándares de habitabilidad: calidad en la vivienda, el entorno inmediato y el conjunto habitacional. https://d1wqtxts 1xzle7.cloudfront.net/41210291/5569b54 
$008 \mathrm{aec} 2268$

30359d4.pdf20160115-19908-

1gn1xlz.pdf?1452872540=\&response-content-disposi tion=inlin

e\%3B+filename\%3DParametros_y_estandares_de_habitabilidad.pdf

American Planning Association (2017). Fundamentos de planificación de sitios. APA. https://www.planning.org/planificacion/2/5.htm.

Arboit, M., Magliones, D., y Fontanive, D. (2015). Situación actual y cambios recientes en los índices de vegetación (vis) en ciudades forestadas con climas secos: caso área metropolitana de Mendoza, Argentina. Urbano, 21(38), 8-35. https://doi.org/10.22 320/07183607.2018.21.38.02

Arendt, H. 2009. La condición humana. Paidós.

Baena, G. (2017). Metodología de la investigación. (3 ${ }^{\text {era }}$ Ed.). Grupo Editorial Patria. Banco Interamericano de Desarrollo [BID]. (2021, 6 de enero). Estudio del Banco Internacional de Desarrollo: Estudio en América Latina y el Caribe sobre creciente déficit de vivienda https://www.iadb.org/es/noticias/estudio-del-bidamerica-latina-y-el-caribe -encaran-creciente-deficit-de-vivienda

Bueno, M. (2018). Aristóteles y el ciudadano. Tópicos (México), 54, 11-45. https://doi.org/ 10.21555/top.v0i54.892

Caballero, J., Pérez, M., y Gómez L. (2017). Percepción de habitabilidad en la vivienda precaria: caso zona metropolitana Oaxaca, México. Revista Contribuciones a las Ciencias Sociales. http://www.eumed.net/rev/cccss/2017/03/vivienda-precariamexi co.html

Castro, M., Romero, L., Borré, C., y Anguiano, C. (2001). Habitabilidad, medio ambiente y ciudad. Ciudades, $13(51), \quad$ 10-18. https://biblat.unam.mx/es/revista/ciudades/articulo /habitabilidad-medioambiente-y-ciudad

Corral-Verdugo, V., Barrón, M., Cuen, A., y Tapia-fonllem, C. (2011). Habitabilidad de la vivienda, estrés y violencia familiar. Psycology, 2(1), 3-14. 10.1174/21711971179 4394644

Cruz, R. (2018). Modelo bioético para el análisis de la habitabilidad en la vivienda [tesis de postgrado, Universidad Autónoma del Estado de México]. Archivo Digital Universidad Autónoma del Estado de México. http://hdl.handle.net/20.500.11799/ 80223

Cruz-Muñoz, F., e Isunza, G. (2017). Construcción del hábitat en la periferia de la Ciudad de México. Estudio de caso en Zumpango. Revista EURE - Revista de Estudios Urbano Regionales, 43(129), 187-207. http://www.eure.cl/index.php/eure/article/ view/1594/ 992

D’Alençon, O., Justiniano, C., Márquez, F., \& Valderrama, C. (2008). Parámetros y estándares de habitabilidad: calidad en la vivienda, el entorno inmediato y el conjunto habitacional. En Camino al Bicentenario Propuestas para Chile. Santiago de Chile.

Gazmuri, P. (2013). Familia y habitabilidad en la vivienda. Aproximaciones metodológicas para su estudio desde una perspectiva sociológica. Arquitectura y 
Urbanismo, 34(1), 37-42. http://scielo.sld.cu/scielo.php?pid=S1815$58982013000100004 \&$ script $=$ sci_abstract

H Congreso de la Unión (1983). Nueva Ley publicada en el Diario Oficial de la Federación el 5 de enero de 1983. Congreso de los Estados Unidos Mexicanos.

Hastings, I. (2008). El problema cualitativo en la producción del hábitat popular en la ciudad de México: análisis cualitativo de la vivienda popular. Informes de la Construcción, 60(511), 25-40. http://informesdelaconstruccion.revistas.csic.es/in dex.php/informes delaconstruccion/article/viewArticle /744

Hastings, I. (2015). La homogeneización de la diversidad cultural en la vivienda. Portavoz http://www.portavoz.tv/laomogenizacion-de-la-diversidad-cultural-enla-vivienda/

Hernández, R., Méndez, S., Mendoza, C., y Cuevas, A. (2017). Fundamentos de investigación. McGraw Hill Education.

Instituto de la Vivienda [INVI]. (2021, 7 de enero). Bienestar habitacional: Guía de diseño para un hábitat residencial sustentable. INVI FAU Universidad de Chile.

Instituto Nacional de Estadísticas y Censos [INEC]. (2021, 8 de enero). Resultados Censo $\begin{array}{llll}\text { de Población } & y & \text { Vivienda }\end{array}$

http://www.inec.gob.ec/cpv/index.php?option=com_content\& view $=$ article $\& \mathrm{id}=222 \&$ Itemid $=66 \&$ lang $=\mathrm{es}$

Landázuri, A., y Mercado, S. (2004). Algunos factores físicos y psicológicos relacionados con la habitabilidad interna de la vivienda. Medio Ambiente y Comportamiento $\begin{array}{lllll}\text { Humano, } & 5(1 & \text { y } & 2\end{array}$ https://mach.webs.ull.es/PDFS/Vol5_1y2/VOL_5_1y2_e .pdf

Link, F., y Greene, M. (2020). Comunidades, sociabilidad y entorno construido. Revista $\begin{array}{llll}\text { Bitácora Urbano } & \text { Territorial, } & 31(1), & 7-1 .\end{array}$ https://doi.org/10.15446/bitacora.v31n1.91 144

Londoño, D. (2016). Estructura de indicadores de habitabilidad del espacio público en ciudades latinoamericanas. Revista de Arquitectura, 18(2), 6-26. http://dx.doi.org/ 10. 14718/RevArq.2016.18.2.2

Maslow, A. (1975). Motivación y personalidad. Sagitario.

Mena, E. (2011). Habitabilidad de la vivienda de interés social prioritaria en el marco de la cultura. Reasentamiento de comunidades negras de Vallejuelos a Mirador de Calasanz en Medellín, Colombia. Cuadernos de Vivienda y Urbanismo, 4(8), 296314. https://revistas.javeriana.edu.co/index.php/cvyu/article/view/5477/4413

Molar, M., y Aguirre, L. (2013) ¿Cómo es la habitabilidad en viviendas de interés social? Caso de estudio: fraccionamientos lomas del bosque y privadas la torre en Saltillo,

Coahuila. RICSH Revista Iberoamericana de las Ciencias Sociales y

Humanísticas, 2(4), 1-26. https://www.redalyc.org/articulo.oa?id=503950746004

Moreno, S. (2008). La habitabilidad urbana como condición de calidad de vida. Palapa, $3(2)$, 47-54.

http://redalyc.uaemex.mx/src/inicio/ArtPdfRed.jsp?iCve=94814774007

Navarro, V., y Calderón, R. (2014). Espacios habitacionales, dinámicas sociales y calidad de vida. RIDE Revista Iberoamericana para la Investigación y el Desarrollo 
Educativo, $5(9)$

28-144.

https://dialnet.unirioja.es/servlet/articulo?codigo $=4932612$

Páramo, P., Burbano, A., Jiménez, B., Barrios, V., Pasquali, C., Vivas, F., Moros, O., Alzate, M., Jaramillo, J., y Moyano, E. (2018). La habitabilidad del espacio público en las ciudades de América Latina. Avances en Psicología Latinoamericana, 2 ,

345-362.

http://dx.doi.org/10.12804/revistas.urosario.edu.co/apl/a.4874

Rodríguez, D., y Villazón, R. (2021). Sistema de habitabilidad. Principios técnicos del proyecto de arquitectura. Universidad de Los Andes. https://uniandes.Ipublishcen tral.com/product/sistemas-de-habitabilidad

Rosabal, R., y Torres, V. (2020). El proceso de enseñanza-aprendizaje de la asignatura química desde la dimensión ambiental. D\&E. Publicación del CEPUT, 21(2), 268-288. https://dialnet.unirioja.es/descarga/articulo/7682678.pdf

Salinas, L., y Pardo, A. (2020). Política de vivienda y habitabilidad en la periferia de la zona metropolitana del Valle de México. Revista de Geografía Norte Grande, 76, 51-69. https://doi.org/10.4067/S0718-34022020000200051.

Spink, M., Martins, M., Silva, S., \& Silva, S. (2020). O Direito à Moradia: Reflexões sobre Habitabilidade e Dignidade. Psicologia: Ciência e Profissão, 40, 1-14. https://doi. org/10.1590/1982-3703003207501

Stockebrand, J., y Stockebrand, R. (2021). Villa Marta Brunet y la ontología del habitar: habitabilidad de proyectos de viviendas sociales en Santiago de Chile. Resonancias, 10, 115-127.10.5354/0719-790X.2021.60942

Tarchópulos, S., y Ceballos, R. (2003). Calidad de la vivienda dirigida a los sectores de bajos ingresos en Bogotá. CEJA.

Usobiaga, E., Guerra, O., y Meer, A. (2017). Desigualdades espaciales de habitabilidad en ciudades patrimoniales. Aplicación de indicadores de seguimiento a las ciudades de San Gabriel y Sangolqui (Ecuador). Boletín de la Asociación de Geógrafos Españoles

75.

file:///C:/Users/DELL/AppData/Local/Packages/Microsoft.Microsof

tEdge_8wekyb3d8bbwe/TempState/Downloads/Dialnet-

DesigualdadesEspacialesde HabitabilidadEnCiudadesPa-6257268\%20(2).pdf

Vaca, O. (2015). Las condiciones de habitabilidad en la vivienda social del modelo metrovivienda 1991 - 2012, caso de estudio: ciudadela nuevo Usme [Tesis de postgrado, Universidad Nacional de Colombia]. Archivo Digital Universidad Nacional de Colombia. https://repositorio.unal.edu.co/handle/unal/54731

Valderrama, S. (2014). Pasos para elaborar proyectos de investigación científica. San Marcos.

\section{PARA CITAR EL ARTÍCULO INDEXADO.}

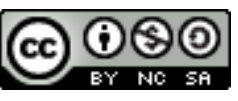

Muñoz Chavarría, Y. G., Domínguez Gutiérrez, J., \& Briones Ordoñez , O. V. (2021). Propuesta de herramienta para la medición de habitabilidad en viviendas en el Ecuador. Magazine De Las Ciencias: Revista De Investigación E Innovación, 6(1), 126. https://doi.org/10.33262/rmc.v6i1.1158 